\title{
EL CONCEJO ABIERTO EN LAS ALDEAS DE A LIMIA
}

301.185 .2 (46. Galicia)

por

José Fariña Jamardo

SUMARIO: I. SIGNIFICACION DEL CONCEJO ABIERTO.-II. LA COMARCA DE A LIMIA.-III. ORGANIZACION MUNICIPAL: FORMAL E INFORMAL.-IV. LOS CONCEJOS ABIERTOS EN LAS ALDEAS DE A LIMIA: 1. Definición. 2. Convocatoria. 3. Notificación. 4. Concurrencia y CONSTItUCión. 5. DesarroLLO Y ACUERDOS. 6. EJECUCIÓN.-V. CLASES DE CONCEJOS ABIERTOS: 1. CONCEJO-PRESTACIÓN. 2. CONCEJO-FIESTA. 3. CONCEJO GENERAL.-VI. REALIZACIONES COMUNITARIAS.-VII. CONCLUSIONES.

\section{SIGNIFICACION DEL CONCEJO ABIERTO}

Que el Concejo abierto, como forma de gobierno local, tiene una existencia cierta, aunque limitada, y una considerable tradición, tanto en nuestro país como en los demás de Europa, es un hecho contrastado e indubitado; como lo es, igualmente, que el verdadero arquetipo de la democracia: la democracia pura y natural, la democracia directa, es la que se practica en el Concejo abierto, en el que intervienen y deciden la totalidad de los vecinos de una Entidad o Comunidad local. 
Pero también es verdad contrastada, que la práctica de la democracia pura mediante el Concejo abierto tuvo que ser sustituida, ya en los tiempos de Roma, por la democracia representativa, cuando las Comunidades locales territoriales domiciliaron un número de vecinos que imposibilitaba el ejercicio y práctica continuada de la democracia natural y originaria.

No obstante, en las pequeñas Entidades locales, en las aldeas, parroquias y Municipios de escaso vecindario, subsistió la asamblea vecinal o Concejo abierto durante siglos, y concretamente en España, su existencia y ejercicio ha sido reconocido y establecido, a pesar de las corrientes doctrinales y críticas adversas, en las regulaciones legales que de las Entidades locales se hicieron en este siglo Xx, desde el Estatuto municipal de 1924, hasta el Proyecto de Ley de Bases de 1981, pasando por la Ley municipal de 1935, la de Bases de 1945, la Ley de Régimen local de 1950 y su Texto Refundido de 1955, si bien con criterios restrictivos en cuanto al número de habitantes de los Municipios y Entidades en los que el Concejo abierto puede ser instituido, y que de los mil o los quinientos del Estatuto de 1924 y de la Ley municipal de 1935, baja a los cien del Proyecto de 1981, aunque reconociendo siempre su subsistencia y establecimiento en aquellos Municipios que tradicionalmente venían rigiéndose por esta forma peculiar de gobierno local.

Pero no es el objeto de este trabajo el tratar de las peculiaridades y subsistencia del Concejo abierto en los Municipios españoles, sino el de estudiar esta forma de gobierno local en las Entidades infra-municipales que aun siendo Entidades de población territoriales claramente singularizadas y determinadas, no constituyen $\mathrm{Mu}$ nicipio, ni están reconocidas legalmente, a no ser a efectos poblacionales y estadísticos; limitándonos, por otra parte, a una zona territorial determinada, y a las Entidades que se asientan en una Comarca geográfica definida, como es la de A Limia, en la Provincia de Orense, dada la singularidad que ofrecen aun dentro de la Comunidad Autónoma de Galicia.

\section{LA COMARCA DE A LIMIA}

La componen los diez Ayuntamientos que integraban el antiguo Partido judicial de Xinzo de Limia, a saber: Baltar, Blancos, Calvos de Randín, Xinzo de Limia, Porqueira, Reiriz da Veiga, Sandiás, 
Sarreaus, Trasmiras y Vilar dos Santos, que en el Censo de 1970 sumaban una población de 39.040 habitantes de derecho, distribuidos en 250 Entidades singulares de población, que el Nomenclátor oficial califica como lugares o aldeas, a no ser las de Reiriz da Veiga y Xinzo de Limia, que tienen la categoría de villa. En cuanto a la diferenciación o distinción entre lugar y aldea, y como ya tenemos demostrado, no existe en la realidad, usándose uno u otra para denominar Entidades del mismo signo y características, por lo que nosotros utilizaremos en este trabajo la de aldea.

De las 250 Entidades singulares de población, sólo una, la de Xinzo de Limia, con sus 3.380 habitantes, superaba en el Censo de 1970 la cifra de los 1.000 habitantes, y un buen número de ellas no alcanzaban siquiera los 100 habitantes. La Comarca de A Limia es ribereña de la laguna Antela - hoy en gran parte desecaday del río Limia -el famoso río del olvido-, que la atraviesa. Comarca esencialmente agrícola y ganadera, y con una población asentada en pequeñas y dispersas Entidades de población, que inicialmente se agrupan en 80 parroquias, según se desprende del propio Nomenclátor.

De acuerdo con la legalidad municipal vigente, las 250 Entidades singulares de población que según el Nomenclátor oficial existen, aunque en la realidad su número sea mayor, integran los diez Municipios y Ayuntamientos referidos, en la siguiente proporción: Baltar, 15; Blancos, 21; Calvos de Randín, 19; Xinzo de Limia, 33; Porqueira, 30; Reiriz da Veiga, 58; Sandiás, 18; Sarreaus, 22; Trasmiras, 20, y Vilar dos Santos, 14. En cuanto a las parroquias que componen cada uno de estos Municipios son, respectivamente: siete, siete, nueve, veinte, seis, ocho, tres, nueve, nueve y dos.

Conforme a lo que dispone la vigente legislación de Régimen local, cada uno de los diez Municipios de A Limia tiene su propio Ayuntamiento compuesto por el Alcalde y el número de Concejales que según su respectiva población le corresponde, pero al no existir ninguna Entidad local menor oficialmente reconocida, tanto las parroquias como las aldeas o lugares, aunque existen de hecho, no tienen reconocimiento legal expreso como Entidades municipales. A pesar de ello, en esta Comarca, como en las restantes de Galicia, existe una organización de gobierno local de hecho, más ajustada a la realidad territorial y poblacional, que complementa o sustituye a la legal u oficial, y de la que nos vamos a ocupar a continuación. 


\section{ORGANIZACION MUNICIPAL: FORMAL E INFORMAL}

Como es obligado, el Ayuntamiento de cada uno de los diez. Municipios de A Limia se asienta en la capital respectiva, cuya población, salvo en el caso de Xinzo de Limia, que supera los. 3.000 habitantes, oscila entre los 97 de Blancos y los 608 de Baltar.

Dado el número de Entidades singulares de cada Municipio y su dispersión, ni el Alcalde ni el Ayuntamiento pueden estar presentes. en las parroquias y aldeas que componen el término municipal, ni estas Entidades representadas en el Consistorio por ser muy inferior el número de Concejales que componen el Ayuntamiento que el de Entidades; cosa distinta sería si las concejalías se estableciesen por parroquias. Para que exista un representante del Ayuntamiento, bien en la parroquia, la aldea o grupo de aldeas, el Alcalde del Municipio nombra Alcaldes de barrio, con las limitadas facultades que la legislación municipal señala, y a quienes los vecinos tradicionalmente llaman Pedáneos, desconociendo, claro está, la diferenciación legal que existe entre Alcalde de barrio y Alcalde pedáneo, si bien acertando, como veremos, en cuanto a la denominación que le asignan.

Desde el establecimiento de los Ayuntamientos democráticos. y, por regla general, los Alcaldes de barrio - Pedáneos les llamaremos de ahora en adelante, aunque legalmente no lo sean- son elegidos y propuestos por las parroquias o Entidades en que tradicionalmente existen, y confirmados por el Alcalde que preside el Ayuntamiento. Cuando esto no sucedía así, muchas veces coexistían el Pedáneo oficial, designado por el Alcalde, y el elegido por la parroquia o las aldeas, que era al que verdaderamente acataban los vecinos. Pero esta conexión legal y oficial no es suficiente, puesto que cada Entidad institucional o singular: parroquia o aldea, constituye un grupo social característico, asentado en un territorio delimitado, con problemas y aspiraciones propias, que a veces se contraponen a las de la capitalidad municipal o a las del Consistorio, porque, además, estas Entidades tienen su propio Consistorio o asamblea, que es el Concejo abierto.

Por esta causa, en la práctica y desde siempre, o si se quiere desde que existe el actual sistema uniformado de gobierno local, conviven una organización legal o formal con un Alcalde y un Ayuntamiento o Corporación representativa para todo el término munici- 
pal, y una organización complementaria o informal en determinadas parroquias, grupos de aldeas o aldea, con un Pedáneo y un Concejo abierto, es decir, una organización paralela, actuando en un ámbito territorial más reducido, con un Concejo que delibera y adopta acuerdos y un Pedáneo que los ejecuta, en similitud con lo que hacen el Ayuntamiento y su Alcalde, si bien, el Concejo abierto o menor practica, como veremos, la democracia directa, y el Concejo mayor o Ayuntamiento, la representativa.

En la Comarca de A Limia, a diferencia de lo que ocurre en la mayor parte de las de Galicia, el Pedáneo no suele ser de parroquia -aunque también existen algunos que lo son-, sino de aldea o de un grupo de aldeas. Hecho que obedece a un conjunto de causas y circunstancias que con detalle examinamos en nuestro libro Concellos abertos na Limia, al igual que la persistencia a través de los siglos de las parroquias y aldeas o Entidades singulares de población, como lo demuestra que las parroquias sean prácticamente las mismas desde el siglo xv, y que la diferencia entre las Entidades singulares de población censadas en el año 1860 y las consignadas en el Nomenclátor de 1970 sea solamente de 18.

Las circunstancias expuestas determinan que en A Limia, para el gobierno de la Vida local, coexista con la organización legal y formal de los diez Alcaldes y los diez Ayuntamientos, una organización informal, a nivel de parroquia, aldea o grupo de aldeas, con Concejo abierto y Pedáneo, en cada caso, y cuyo resumen por Municipios es el siguiente:

\begin{tabular}{|c|c|c|c|}
\hline MUNICIPIO & $\begin{array}{c}\text { Entidades } \\
\text { singulares } \\
\text { que lo } \\
\text { forman }\end{array}$ & Pedáneos & $\begin{array}{l}\text { Conceios } \\
\text { abiertos }\end{array}$ \\
\hline 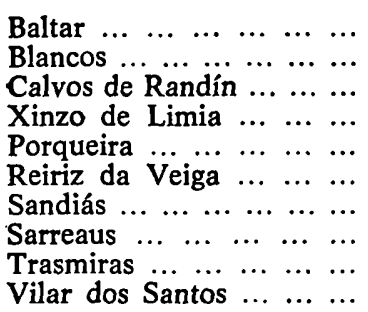 & $\begin{array}{l}15 \\
21 \\
19 \\
33 \\
30 \\
58 \\
18 \\
22 \\
20 \\
14\end{array}$ & $\begin{array}{r}16 \\
14 \\
19 \\
31 \\
13 \\
29 \\
16 \\
16 \\
17 \\
9\end{array}$ & $\begin{array}{r}16 \\
14 \\
19 \\
31 \\
13 \\
29 \\
16 \\
16 \\
17 \\
9\end{array}$ \\
\hline Totales $\ldots \ldots \ldots \ldots$ & 250 & 180 & 180 \\
\hline
\end{tabular}


Es decir, que además de los diez Alcaldes y los diez Ayuntamientos, las 250 Entidades singulares de población de A Limia disponen para su gobierno de 180 Pedáneos y 180 Concejos abiertos o asambleas vecinales. De estos 180 Concejos abiertos, 32 lo son de parroquia, 29 de más de una aldea y 119 de una sola aldea o Entidad singular de población. El número de aldeas agregadas a otras para. tener Pedáneo y Concejo abierto es de 70 , y su distribución por Ayuntamientos puede apreciarse en el cuadro-resumen anterior. En el Ayuntamiento de Baltar, en cambio, existe un Pedáneo y un Concejo abierto más que el número de Entidades o aldeas, ya que en la. Entidad Boullosa, que se compone de dos barrios, existe uno para cada uno de ellos.

\section{LOS CONCEJOS ABIERTOS EN LAS ALDEAS DE A LIMIA}

\section{DEFINICIÓN}

El Concejo abierto es una reunión o asamblea de los vecinos de una Entidad de población - parroquia, aldea, grupo de aldeas-, que se viene realizando desde tiempo inmemorial en las aldeas de A Limia, en donde existe también Pedáneo, y que se rige por la costumbre, al margen de las Leyes que regulan el Régimen local. Los protagonistas únicos del Concejo abierto son los vecinos que deliberan en él sobre los asuntos que afectan a la Comunidad, adoptando en relación con los mismos las consiguientes resoluciones que obligan a todos los vecinos de la aldea o grupo de aldeas: respectivos.

Conviene precisar que estos rasgos son generales para todos los Concejos abiertos que se celebran en la Comarca, la mayoría de aldea, aunque algunos de grupo de aldeas y de parroquia, si bien existen ciertos matices o singularidades, que iremos poniendo de relieve en los siguientes apartados; advirtiendo que la fuerza de obligar de sus acuerdos no se fundamenta en las Leyes, sino en la conciencia vecinal, que aún es muy fuerte en estas pequeñas colectividades, en donde el «estar a bien» con los vecinos tiene una gran importancia en todos los sentidos.

En el lenguaje de las gentes de la Comarca se habla mayormente de Concejo (Concello), sin adjetivo, porque en realidad no lo nece- 
sita, ya que siempre es abierto (aberto). Y si no lo fuese para ellos dejaría de ser Concejo. Ahora bien, Concejo significa también, o quiere decir, reunión o asamblea vecinal para imponer la prestación personal, o exclusivamente equivale a prestación personal. Tan es así que a la prestación personal la denominan: Concejo. Estar trabajando en prestación personal comunitaria, es estar en Concejo. Por eso los vecinos hablan y dicen que estuvieron en Concello cuatro días o una semana entera.

Y pude comprobarlo cuando encontrándome en la Comarca realizando el trabajo de campo sobre los Concejos abiertos, en el mes de abril de 1981, en la Entidad de San Lourenzo, parroquia de Abelendo, del Ayuntamiento de Porqueira, le pregunté a los vecinos allí reunidos que cuanto tiempo duraban los Concejos, y me contestaron que tanto como el que durasen los trabajos a realizar. Y lo mismo me respondieron los Pedáneos de Lamas, Baronzás y Gudes de Guntimil, o los Alcaldes de los Ayuntamientos de Baltar, Blancos y Porqueira, entre otros. Pero si bien los Concejos se celebran la mayoría de las veces para deliberar en orden a la ejecución de las obras y servicios de desarrollo comunitario, también se convocan para deliberar y resolver acerca de las demás cuestiones que afectan a la Entidad y a sus vecinos, como examinaremos con detalle más adelante.

\section{Convocatoria}

La realiza el Pedáneo, bien por propia iniciativa o a petición de los vecinos, cuando entiende que la reunión del Concejo abierto es necesaria. También puede convocarlo a petición del Alcalde del Ayuntamiento, cuando la primera autoridad del Municipio quiere establecer contacto a través de la organización informal con los vecinos de la Entidad, para informarles sobre asuntos que les afectan de una manera directa, o para pedirles colaboración en la ejecución de determinadas obras, o en la implantación y desarrollo de servicios de utilidad general municipal, o específica de la aldea o parroquia.

No están determinadas a priori fechas fijas para la celebración de los Concejos abiertos, por lo cual no se puede hablar de Concejos ordinarios o extraordinarios, ya que de hecho todos revisten este último carácter, si establecemos una comparación con las 
sesiones que celebran los Ayuntamientos. No hay más orden del día para la reunión o asamblea que el que lleva in mente el Pedáneo, o el que éste ha convenido con algún vecino o grupo de vecinos, si bien el Pedáneo, lógicamente, procura que el asunto o asuntos a tratar tengan la debida importancia para que todos los vecinos que se reúnan en el Concejo no pierdan su tiempo en balde. No existe regularidad alguna en cuanto a las fechas de celebración y número de Concejos a celebrar, puesto que lo mismo convocan uno o dos en el año, que una docena.

A pesar de lo dicho, en muchas aldeas de la Comarca se celebran Concejos de carácter anual, que tienen lugar en la época de la cosecha y para tratar del arreglo de los caminos carreteros o de servidumbre, o, como sucede en las aldeas del Ayuntamiento de Calvos de Randín, cuando se verifica la recogida de la hierba para ensilarla. En el Municipio de Sarreaus, las aldeas de mayor población vienen celebrando Concejo cada dos o tres meses, y las más pequeñas solamente dos o tres al año; mientras que en el de Reiriz da Veiga, igual pasan sin celebrar Concejo varios meses, que de pronto y por la fuerza de las circunstancias convocan tres y hasta cuatro en un solo mes. En realidad, la celebración de estas asambleas vecinales que son los Concejos abiertos, queda sujeta a la existencia de asuntos que afecten a la Comunidad.

\section{NOTIFICACIÓN}

La realización de la misma, que los vecinos de la Comarca denominan desde siempre: empena-lo Concello, se efectúa de diversas formas. En aquellas Entidades en las que existen ayudantes o auxiliares del Pedáneo, conocidos como celadores o vigairos, son éstos los encargados de realizar la notificación — verbal, se entiendede que se va a celebrar el Concejo abierto, avisando para ello a los vecinos y haciéndolo de puerta en puerta.

Si el Pedáneo no dispone de ayudantes o vigairos, las notificaciones o avisos para la celebración del Concejo las hace directamente él mismo. En algunas aldeas, y siguiendo la costumbre establecida, dos o tres mujeres, con cuarenta y ocho horas de antelación o en la víspera de la celebración del Concejo abierto, van avisando de casa en casa a los vecinos, transmitiéndoles el recado del Pedáneo. Dichas mujeres, que o son viudas sin hijos, o viven solas, o no se 
encuentran en buena situación económica, por realizar la notificación, o lo que es lo mismo, empena-lo Concello, quedan exentas de la prestación personal e incluso, en ciertos casos, de cualquier otra obligación de carácter comunitario. También en otras aldeas, como. en la de San Lourenzo, y para descargar al Pedáneo de sus no pocas. obligaciones, notifican la celebración del Concejo uno o dos vecinos, por riguroso turno entre todos los de la Entidad.

A no ser en los casos de urgencia, la notificación de la convocatoria a Concejo debe hacerse, al menos, con veinticuatro horas de antelación. Pero además de la notificación verbal de casa en casa, el anuncio de celebración de Concejo se efectúa también mediante el toque de campana, ya sea de la iglesia parroquial o de la ermita de la aldea de que se trate. El toque de la campana es para indicar la celebración de la reunión o de que va a dar comienzo el Concejo abierto, teniendo cada aldea una manera especial de ejecutarlo, pues mientras los Pedáneos de Lamas, Baronzás y Gudes me aseguraban que el toque en sus aldeas era más apurado que el empleado. para anunciar la misa, los vecinos de San Lourenzo me dijeron que el toque en su aldea era más pausado, y que el hacerlo más. lento que el empleado para llamar a la celebración de la misa obedecía a que si fuese más apurado, los vecinos creerían que se trataba de un incendio y que las campanas llamaban para apagarlo.

Por regla general, es el Pedáneo el que toca la campana llamando. a Concejo, finalizando el mismo con tres badaladas o toques más fuertes, que son la señal de que el Concejo va a empezar. Ahora bien, conviene aclarar que el tañer de la campana o campanas es doble, con un toque primero para avisar, y otro posterior para que acudan ya a la reunión que se inicia. $O$ sea, un toque que significa: celebramos Concejo, y otro que quiere decir: empezamos ya el Concejo. En algunas aldeas de la Comarca, como en Quilmelas, en el Ayuntamiento de Reiriz da Veiga, en lugar de tocar las campanas, convocan el Concejo abierto a toque de cuerno, sustituyendo las tres badaladas que señalan el comienzo del mismo, por tres toques largos de cuerno soplados uno detrás de otro.

\section{CONCURRENCIA Y CONSTITUCIÓN}

En general, la concurrencia a estos Concejos abiertos suele ser bastante numerosa. En unas aldeas es más completa que en otras, pero las informaciones que me fueron facilitadas hablan de que 
la mayoría de los vecinos concurren, aunque no siempre ni en todas las aldeas, siendo en las del Ayuntamiento de Sandiás donde las ausencias son más abundantes.

Sobre este particular es significativo lo que viene ocurriendo en los Concejos abiertos de Baronzás, muchos de cuyos vecinos no son labradores, sino obreros o empleados en la colindante villa de Xinzo de Limia y que, sin embargo, y hasta ahora, cuando no pueden asistir mandan a un representante y aceptan y cumplen los acuerdos adoptados en el Concejo. La representación por un familiar o por otro vecino cualquiera está generalmente admitida en los Concejos de la Comarca y no hacen falta papeles justificativos, ni más exigencia y requisito que decirle al Pedáneo: vengo en nombre de Fulano. Todos se conocen y todos responden de sus manifestaciones y poderes.

Constituyen el Concejo abierto todos los vecinos de la aldea o aldeas que comprende, siempre que sean cabezas de familia, o como dicen los comarcanos, cabezas de casa, que son los que tienen derecho a voto. Aunque siendo Concejos abiertos, como son, pueden concurrir a ellos también los demás vecinos mayores de edad, e incluso los menores, si bien como espectadores, ya que no tienen derecho a votar.

Los cabezas de familia o de casa son aquellos vecinos que tienen puestos a su nombre los bienes de la casa, pudiendo ser, por tanto, el abuelo, el padre o la madre viuda, lo mismo que un hijo casado o soltero que viviendo con sus padres y hermanos en la casa, sea titular de los bienes de la misma. Por ejemplo, si en una casa viven juntos el padre y el hijo, y el padre tiene hechas y firmadas las partijas, y el hijo dispone ya de su herencia y mantiene a su padre, el cabeza de casa y de familia es el hijo.

En época pasada, en algunas aldeas, sólo tenían derecho a voto en Concejo los que tuviesen xugada, o sea, labranza propia y una pareja de bueyes o vacas. Pero ahora, y en determinadas cuestiones, incluso pueden votar todos los mayores de edad. Conviene señalar que en este orden de cosas cada aldea tiene su sistema y costumbres, aunque la regla general es, como ya tenemos dicho, que sólo tengan derecho a voto en Concejo abierto los cabezas de casa. Y que cada cabeza de casa tenga un voto y sólo uno.

El Concejo abierto se reúne en el lugar tradicionalmente designado para este fin, que lo mismo puede coincidir con la plaza de la Entidad o pueblo, con el horno comunitario, con la escuela, el 
atrio de la iglesia o ermita, la taberna, una calle o el campo de la fiesta. En Gudes y en San Lourenzo, el Concejo se celebra en el centro mismo de la aldea. En Baronzás, en una calle llamada precisamente «Aldea». En Lamas, en el atrio de la iglesia, y en ocasiones a la salida de la misa parroquial. Sin embargo, en San Lourenzo, cuando el Concejo se convoca en domingo, se señala la hora de salida de misa para comenzarlo, pero nunca se celebra en el atrio de la iglesia, sino en el lugar de costumbre, que está situado, como ya dijimos, en el centro de la aldea.

En todas las Entidades de la Comarca, el lugar de celebración del Concejo abierto es siempre el mismo y viene utilizándose desde tiempo inmemorial. En cuanto a la hora de comienzo de los Concejos, aun cuando no esté señalada con carácter de generalidad, podemos decir que la mayoría de ellos se celebran al mediodía o por la noche.

\section{DesarRollo Y acUERDoS}

Después de los toques de campana da comienzo el Concejo abierto, que preside el Pedáneo o el Alcalde del Municipio cuando, por excepción, concurre a él. El Pedáneo no sólo abre el Concejo, sino que dirige las deliberaciones y corta las posibles alteraciones y desviaciones, votando los acuerdos como un vecino más, ya que no tiene voto de calidad para dirimir los posibles empates.

El Pedáneo abre la sesión del Concejo diciendo sencillamente y sin más preámbulos: Señores, vamos a comenzar para tratar de los asuntos siguientes - que enumera-; o: vamos a hablar sobre el arreglo de los caminos, sobre los arbitrios que nos quieren imponer los del Ayuntamiento, sobre la concentración parcelaria, el nombramiento de la Comisión de fiestas, o el asunto que determinase la convocatoria. Una vez que el Pedáneo ha hecho su intervención, hacen uso de la palabra los vecinos que lo soliciten para exponer sus puntos de vista acerca de la cuestión planteada. En ocasiones, se producen fuertes discusiones, y el Pedáneo se puede encontrar un tanto desbordado por las opiniones enfrentadas de los vecinos. $\mathrm{Y}$ es entonces cuando se ve obligado a imponer su autoridad para que las aguas vuelvan a su cauce, y la discusión y la sangre -en sentido figurado, se entiende- no lleguen al río.

Una vez debatido el asunto, si no se consigue la unanimidad, que algunas veces, en efecto, no se consigue, el Pedáneo manifiesta 
que se va a proceder a la votación, en la cual cada cabeza de familia o casa, como ya dijimos, tiene un voto. Seguidamente dice: los que estén de acuerdo con la propuesta hecha, que se pongan a mi derecha, y los que no estén de acuerdo, a la izquierda. Lo hacen así los vecinos asistentes al Concejo, y ya a simple vista puede apreciarse si existe mayoría a favor de la propuesta o si la misma es rechazada. $Y$ en caso de duda es el Pedáneo quien efectúa el recuento de votos.

También puede hacerse la votación por el sistema de levantar la mano los que están de acuerdo, primero, y luego los que no lo estén; siendo también el Pedáneo quien hace el recuento para determinar si se aprueba o rechaza la propuesta. Estos sistemas de votaciones, aunque no se ajusten formalmente a los legalmente establecidos, son los tradicionalmente practicados, y de su resultado se deriva la fuerza de obligar de los acuerdos adòptados.

En bastantes ocasiones, en los Concellos no se llega a efectuar la votación por haberse establecido con antelación el consenso, término ahora tan de moda; o porque a través de las distintas intervenciones se puso de relieve cuál era la voluntad unánime de los vecinos asistentes; o porque ninguno se opone a la propuesta hecha por el Pedáneo, que en muchas de estas aldeas, y como sucede, por ejemplo, en las del Municipio de Trasmiras, es muy respetado por los vecinos y ejerce una indudable influencia sobre ellos.

De cualquier forma, y por cualquier sistema, la mayoría es la que decide siempre, cuando no existe unanimidad, resolviendo la cuestión planteada, o determinando que el asunto quede pendiente para volver a ser examinado en un nuevo Concejo, o en más si fuese necesario, hasta aprobarlo o rechazarlo. De la sesión del Concejo abierto no se levanta acta propiamente dicha, ni se escribe nada acerca de ella. Los vecinos consideran, y la práctica lo demuestra, que no hace falta acta escrita, ya que todos ellos intervinieron en la adopción del acuerdo o acuerdos, y todos los conocen, siendo el Pedáneo, normalmente, o una Comisión de vecinos, en algunos casos, los encargados de ejecutarlos.

\section{EJECUCIÓN}

Los acuerdos adoptados en Concejo abierto obligan a todos los vecinos de la Entidad o Entidades que lo constituyen, tanto si vo- 
taron a favor, como si lo hicieron en contra. La fuerza ejecutiva de estos acuerdos radica en la voluntad de los vecinos, en la conciencia colectiva, y de ella deriva su acatamiento por parte de todos, aun de los que manifestaron su disconformidad con los mismos. $Y$ en este sentido, si el acuerdo fue de imponer la prestación personal para ejecutar obras o servicios, los vecinos que mostraron su oposición a la misma acatan lo acordado y se presentan generalmente a efectuarla en la fecha que les hayan asignado. Si no lo hiciesen tienen que pagar la correspondiente multa o compensación, que ejecuta directamente el Pedáneo; y en caso de negarse el sancionado, se insta su imposición y ejecución por el Alcalde del Municipio, aunque sólo excepcionalmente se recurre a la primera autoridad local con la denuncia, puesto que casi siempre el vecino rebelde acepta pagar la multa o realizar el trabajo o prestación impuesta, en otro día. En algunas aldeas el importe de estas multas se utiliza en comprar vino para obsequiar a los que trabajan en la prestación personal, y en otras, para los gastos comunales o para la celebración de las fiestas patronales.

Hay que admitir que la ejecución de los acuerdos del Concejo abierto, al carecer los mismos de un carácter legal estricto. puede originar problemas que incluso la buena disposición del Alcalde o del Ayuntamiento no sea suficiente para resolverlos. Para obviarlo, además de la fuerza de la tradición y de la costumbre, en estas Entidades suelen formalizarse convenios en los que se establece la obligación de cumplimentar los acuerdos del Concejo abierto y de abonar, en caso de incumplimiento, las compensaciones o multas que se determinan.

\section{CLASES DE CONCEJOS ABIERTOS}

Teniendo en cuenta los asuntos de que se ocupan, podemos distinguir tres clases de Concejos abiertos en la Comarca de A Limia: Concejo-prestación, Concejo-fiesta y Concejo-general. Esta clasificación no supone separación entre los tres tipos, ya que en cualesquiera de ellos, además del asunto principal que los caracteriza, se pueden tratar asuntos que corresponden a los otros dos, ya que realmente no existe más que una sola clase de Concejos abiertos, y si hablamos de tipos es sólo para entendernos en orden a una mejor sistematización y comprensión, ya que de hecho ni siquiera 
se utilizan los nombres con los que los bautizo, pues para los vecinos el Concello es único.

\section{Concejo-PREstación}

Como ya señalé, es el Concejo primario, tradicional, el de la continuidad, el que hizo que la asamblea general de los vecinos no dejase de existir. En este sentido, y para los habitantes de la Comarca de A Limia, Concejo significa lo mismo que prestación personal, como eje y base del deseado desarrollo comunitario, y el único camino posible que tenían para alcanzar un pequeño progreso, dentro de la escasez de medios de que disponían.

No se tiene hecho, y sería muy interesante el realizarlo, un estudio acerca de lo que la prestación personal significó para las aldeas y parroquias del rural gallego, y las realizaciones obtenidas con la misma. En cuanto a las de la Comarca de A Limia haremos una sucinta referencia más adelante.

La mayor parte de los Concejos abiertos que se celebran en las aldeas de A Limia son Concejos-prestación, que están dedicados, en primer lugar, a acordar su imposición, y después establecer con detalle su ejecución. Son Concejos en los que se trata del arreglo de caminos y calles; de la limpieza de las conducciones de agua para riego; de las nuevas obras acordadas y que están realizando; de los turnos de prestación para la reparación del horno; para el cuidado y guarda del toro-semental donde existe, como ocurre en varias aldeas del Municipio de Calvos de Randín; para el encendido y apagado del alumbrado público, o el acompañamiento de los niños de la aldea hasta el lugar en donde los recogen los ómnibus para llevarlos al centro de concentración escolar; para el pastoreo del ganado, y para todo aquello que supone la imposición de una carga de trabajo personal.

Como ya antes señalamos, el Concejo-prestación continúa durante todo el tiempo en que se realizan los trabajos impuestos, estableciendo las tareas que cada vecino ha de realizar al día siguiente, y que dispone el Pedáneo, el cual también les señala las herramientas con las que tienen que presentarse y los lugares donde realizarán la prestación o trabajo. Si además de la prestación personal, se comprende la de transporte, el Pedáneo, igualmente, dispone los carros, tractores, camiones $u$ otros vehículos 
que deberán concurrir. La prestación de carros y tractores se hace por turno riguroso (rolda), si bien en algunas aldeas cuando se necesitan tractores o camiones para las obras a ejecutar, los arriendan, y el importe del alquiler es abonado a escote por todos los vecinos cabezas de casa.

Iniciado el Concejo-prestación, al día siguiente se reúnen de mañana los obligados a efectuarla en su primera jornada, con sus herramientas, carros o tractores, en el lugar convenido, y desde allí, bajo el mando directo del Pedáneo, se dirigen a los lugares donde han de realizar el trabajo. Y lo mismo hacen en días sucesivos, mientras dure la prestación, reuniéndose nuevamente en Concejo por la noche, para disponer los trabajos del día siguiente, al igual que los designados para realizarlos, y la forma como los ejecutarán. La prestación puede ser hecha por el obligado directamente a ella o por una persona que le sustituya, que sea competente y se encuentre en condiciones de desarrollar el trabajo impuesto, haciéndolo con cargo a la persona en cuyo lugar concurre a la prestación.

Ya nos hemos referido a las sanciones que son impuestas a quienes no concurren a la prestación acordada en Concejo. En algunas aldeas esta multa consiste en tener que acarrear carros de piedra para el arreglo de los caminos o en realizar otros trabajos para la comunidad vecinal. Los importes de las multas, cuando son en metálico, los dedican a las necesidades de la aldea 0 para adquirir el vino que distribuyen en ocasiones entre los que trabajan en las obras comunitarias. Sobre este particular nos parece interesante consignar que en algunas Entidades, como las del Municipio de Reiriz da Veiga, acostumbran a dar a los que trabajan en las obras ordenadas por el Concejo, pan y vino, que adquieren no con las multas, sino con el producto de la venta de la ceniza del horno de la Comunidad, que se utiliza para el abono de los prados, y que se adjudica al mejor postor.

\section{CONCEJO-FIESTA}

La denominación no implica que se celebre un Concejo especial para acordar lo concerniente a la celebración de las fiestas de la parroquia o aldea, sino que el tema de las fiestas es uno de los que cada año, y una o más veces, es tratado en Concejo abierto, 
puesto que la organización de las fiestas presenta ciertas singularidades. Así, en Gudes, todos los años, en Concejo, acuerdan el señalamiento de las cuotas con las que cada vecino ha de contribuir para la celebración de las mismas, y que después son recaudadas, puerta a puerta, por la Comisión vecinal que el mismo Concejo designa para ejecutarlas. A los miembros de estas Comisiones de fiestas, les llaman mayordomos, y en las aldeas del Municipio de Sarreaus son nombrados por turno en el Concejo, en número de tres o cuatro, siendo los encargados de todo lo referente a la organización y desarrollo de las fiestas, al igual que de recibir de los vecinos el importe de las cuotas señaladas, que, generalmente, abonan sin muchas protestas, $\mathrm{y}$ esto aun en el supuesto, como sucede en Lamas, de que las cuotas no las imponga el Concejo, y las fije con el carácter de voluntarias la Comisión.

El sistema de imponer cuotas para las fiestas por el Concejo, y el de designar los mayordomos que luego en Comisión son los encargados de recaudarlas, es el más generalizado. Estos mayordomos de fiestas no tienen que ser forzosamente, aunque lo sean la mayoría de las veces, cabezas de casa, pues en algunas Entidades, como sucede en las del Municipio de Vilar dos Santos, el Concejo nombra a mozos o jóvenes mayores de dieciocho años, que integran la Comisión, y que aparte de recaudar las cuotas de los vecinos, incrementan los ingresos destinados a sufragar las fiestas con los procedentes de la explotación del bar que instalan en el recinto festero.

En otras aldeas, la Comisión dispone, además de las cuotas, de los ingresos procedentes de la subasta de las andas de la imagen del Patrón o Patrona para llevarla durante la procesión o meterla de nuevo en la iglesia, y también los de la subasta de puestos de venta $y$ atracciones en el campo de la fiesta. $Y$ ya que venimos hablando de campos de fiesta, diremos que cada aldea tiene el suyo, más amplio o más reducido, mejor o peor conservado, pero propio.

\section{CONCEJO GENERAL}

Podemos considerar como tales aquellos que no se refieren específicamente a los temas de la prestación personal o de las fiestas, o en los que además de tratar de estos dos asuntos, se debaten 
otros distintos. Son, por tanto, aquellos Concejos abiertos que se ocupan de los asuntos que afectan a la Comunidad vecinal en una doble vertiente: Los que le son impuestos por las leyes y reglamentaciones generales a través del Ayuntamiento: vacunación de personas o de animales; sacrificio domiciliario de ganado porcino; disposiciones y normas sobre sanidad y educación; oficios, bandos y resoluciones de la Alcaldía; quintas, suscripciones, repartimientos $\mathrm{y}$, hasta no hace aún muchos años, cupos de entrega forzosa, requisas, aportaciones y similares. $Y$ los que los vecinos promueven o demandan para mejorar los servicios de la aldea: pavimentación, alcantarillado, abastecimiento de agua, alumbrado, cementerio, parroquia, horno, era, escuelas, teleclubs, etc.; para el mejor aprovechamiento de sus bienes públicos o privados, como pueden ser los de pastos o montes, o la concentración parcelaria.

Los primeros son más bien para conocimiento, aunque este conocimiento lleve anejo el cumplimiento, y los segundos, de iniciativa propia y siempre referida a cuestiones que afectan directamente a la Entidad, son aquellos de los que pueden derivarse para la aldea y sus vecinos un mejor y más efectivo desarrollo comunitario.

\section{REALIZACIONES COMUNITARIAS}

Hasta aquí hemos puesto de relieve no sólo la existencia y funcionamiento en este tercio final del siglo $\mathrm{xx}$ de Concejos abiertos en la Comarca de A Limia, sino la coexistencia en la misma de una organización informal, tácitamente admitida, que sustituye, y en cierto modo complementa, a la legal o formal, en cuanto al gobierno de las Entidades de base: aldeas, grupos de aldeas o parroquias, en su caso. $\mathrm{Y}$ ahora cabe preguntarse si estos Concejos abiertos con sus Pedáneos, y esta organización informal, sirve para algo positivo, si obtiene resultados, o no es más que folklórica y entorpecedora.

Para los Alcaldes de los Ayuntamientos con los que dialogué, la organización informal que representan los Pedáneos y los Concejos abiertos es necesaria en estos Municipios rurales de A Limia, y complementa la acción de los Ayuntamientos y su relación con los administrados, tanto en sentido descendente como ascendente. Por otro lado, la impone la geografía del asentamiento poblacional. 
Pero al mismo tiempo implica la existencia de grupos sociales cohesionados, que tienen conciencia de su identidad como tales, y unos problemas propios, específicos, que en determinados aspectos sólo ellos pueden resolver. Su existencia, además de tradicional, resulta positiva la mayoría de las veces.

A la vista de las realizaciones que en los últimos años han tenido lugar en las Entidades singulares de población de la Comarca, y dado el carácter comunitario de las mismas, tenemos que admitir que esta singular forma de gobierno local ha alcanzado logros y obtenido algunos frutos. En efecto, se han realizado en las aldeas de la Comarca abundantes obras comunitarias, conforme a las características que las mismas deben revestir: ser hechas por iniciativa e impulso de los propios vecinos de cada Entidad, para mejora y beneficio de la respectiva Comunidad. Las más importantes fueron las de abastecimiento de agua, caminos, carreteras o pistas, pavimentaciones, electrificación y alumbrado público, construcción de escuelas y similares, es decir, verdaderas obras para el desarrollo comunitario.

$Y$ nos parece oportuno recalcar el significado que dicho desarrollo debe tener, y su importancia en orden a la posible transformación del nivel de vida y servicios de los núcleos rurales, habida cuenta de que si bien el desarrollo comunitario como doctrina y práctica a escala internacional aparece en los primeros años de este siglo, en las aldeas del rural gallego existe desde siempre. Lo que, en parte, se explica por el hecho de que estas Entidades: parroquias y aldeas, permanecieron aisladas durante siglos y tuvieron que gobernarse por sí mismas, impulsar sus propias iniciativas, trabajos y actividades para poder subsistir, y aunque muy lentamente avanzar mediante la creación de servicios colectivos: hornos, molinos, corrales, eras, caminos, calles, tabernas, alumbrado, escuelas, fiestas, abrevaderos y lavaderos, al igual que prácticas agrícola-ganaderas de las que aún subsisten algunas en la Comarca, al tiempo que otras nuevas nacen con la técnica y los avances de nuestros días, como el establecimiento de turnos vecinales (roldas) para encender y apagar el alumbrado público de cada aldea, o para conducir a los niños hasta el medio de transporte que los trasladará a los nuevos, y casi siempre alejados, centros de enseñanza.

El Concejo abierto, por su misma contextura, ofrece un marco adecuado para el posible desarrollo comunitario, y las prestaciones, tanto personales como de otro tipo, en ellos acordadas, han hecho 
posible la implantación o mejora de una serie de servicios fundamentales de los que ya hicimos mención, y que no serían posibles sin la cooperación y el esfuerzo de estas colectividades vecinales primarias.

\section{CONCLUSIONES}

De lo que llevamos dicho, se deducen como más significativas las siguientes:

a) El Concejo abierto es una institución aún vigente en las aldeas de A Limia, al igual que en otras muchas parroquias y aldeas de Galicia, que existe desde tiempo inmemorial, y que si bien se confunde a veces con la prestación personal, aun siendo éste uno de los asuntos que con mayor frecuencia se considera en dichos Concejos, no es el único, ya que materia de los Concejos abiertos son todos los asuntos que afectan a la colectividad, aun cuando la prestación haya sido una de las motivaciones que influyeron notoriamente en la subsistencia del Concejo a través de los siglos.

b) Estos Concejos abiertos se celebran en todas las aldeas de A Limia en las que existe Pedáneo. Conviene precisar, sin embargo, que el número de aldeas de la Comarca, según el Nomenclátor, es de 250, y que de ellas solamente tienen Concejo abierto y Pedáneo, 180 , por lo que 70 se agrupan con otras limítrofes para constituir una unidad a este fin, admitida por los vecindarios respectivos, lo que no impide que si varían las circunstancias puedan desagruparse para tener Pedáneo y Concejo propios, al igual que aldeas que hoy los tienen pueden dejar de tenerlos por agruparse con otra u otras.

c) Pedáneos y Concejos abiertos constituyen de hecho una organización informal superpuesta, o más bien paralela, con la organización formal que la Ley establece. Si tenemos en cuenta la dispersión de las Entidades de población y sus características, la organización informal referida es necesaria, y en la práctica puede constituir una ayuda para los Alcaldes y Corporaciones municipales, siempre que las mismas respeten los Concejos abiertos y mantengan su independencia. 
d) El Concejo abierto no sólo representa el ejercicio de la democracia más genuina, sino que a través del mismo, las aldeas rurales de Galicia pueden alcanzar el desarrollo que tanto necesitan, habida cuenta que el desarrollo que puede impulsar el Concejo abierto reúne las características del desarrollo comunitario concebido, como quiere Ander EGG, de una forma equilibrada e integral, teniendo como último objetivo "todo hombre y todos los hombres", ya que es en estas aldeas rurales de A Limia, y en las de toda Galicia, donde se cumplen las características que debe tener la Comunidad, según TonNIEs: vida común, verdadera, duradera, como organismo vivo caracterizado en lo rural, y con el énfasis puesto en el parentesco, la amistad y la familiaridad prolongada.

$\mathrm{Y}$ aun cuando las Naciones Unidas definieron el desarrollo comunitario como «el proceso por el cual la propia Entidad participa en la planificación y en la realización de los programas destinados a elevar su nivel de vida», lo que exige la colaboración indispensable entre los gobiernos y el pueblo para hacer dichos programas de desarrollo viables, equilibrados y efectivos, conviene también tener presente que el verdadero desarrollo comunitario requiere la promoción de los intereses y de las actividades sociales de una Comunidad, realizada con el propio impulso y dirección de los vecinos interesados.

e) No sólo estas aldeas tienen todas las características de verdaderas Comunidades, sino que sus Concejos abiertos reúnen y cumplen todos los requisitos que el Decreto 3524/1974 exige para obtener las ayudas que en el mismo se establecen, y que son:

- Libre determinación por los vecinos en la elección de los problemas que deseen resolver.

- Participación y protagonismo de los vecinos en las posibles soluciones a dichos problemas.

- Voluntariedad en la participación y protagonismo citados.

- Facultad de los referidos vecinos en la adopción de acuerdos sobre el hecho de organizarse y de elegir las personas que hayan de constituir la Comisión gestora de la acción comunitaria.

- Ejecución directa de las obras por los vecinos con su aportación personal y económica. 
f) En consecuencia, creemos que los Concejos abiertos y sus peticiones y acuerdos deben ser tenidos en cuenta directamente y, en primer término, en cualquier programa de acción o desarrollo comunitario.

g) En el futuro desarrollo de la Ley de Régimen local por la Comunidad Autónoma de Galicia, se tendrá en cuenta el hecho de la existencia del Concejo abierto y procederá su expreso reconocimiento en aquellas aldeas, parroquias o Entidades de población que no superen los 1.000 habitantes.

h) Este reconocimiento se fundamentará en los siguientes hechos y consideraciones:

- Necesidad de convertir en organización formal o de derecho, una organización informal no reconocida hasta ahora, pero que tiene unas profundas raíces en el cuerpo social del rural gallego.

- Aprovechar una organización vigente y ciento por ciento democrática, que puede impulsar el desarrollo comunitario.

- Dar una efectiva participación en el gobierno local a todas las Entidades existentes, aun a las más pequeñas, a través de la asamblea general de vecinos que es el Concejo abierto.

i) Para que este reconocimiento sea efectivo tendrá que contener las siguientes disposiciones:

- Legalizar el Concejo abierto en todas las aldeas en las que se viene celebrando, que se regirá por sus tradicionales normas, y admitir y favorecer la constitución de Concejos abiertos en todas las Entidades que lo interesen y que no excedan de los 1.000 habitantes.

- Que los acuerdos de los Concejos abiertos sean ejecutivos y tengan fuerza de obligar para todos los vecinos de la aldea o Entidad de que se trate.

- Que los Ayuntamientos respectivos reciban y conozcan los acuerdos de los Concejos abiertos de su término, y tengan la obligación de apoyarlos e impulsarlos en lo que de ellos dependa.

- La existencia de Concejos abiertos de aldea no limitará ni impedirá la de los Concejos abiertos de parroquia, en los que se agruparán los de las aldeas respectivas cuando los problemas a exa- 
minar y resolver correspondan a toda la parroquia, es decir, a todas las aldeas que la componen.

j) También serán legalizados los Pedáneos, reconociendo su existencia, características y funciones, como representantes de la parroquia o aldea respectiva, siendo elegidos siempre por los vecinos. 


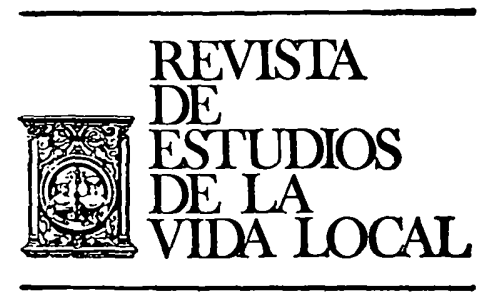

III. ESTADISTICA 
